\title{
DIREITO À EDUCAÇÃO E ESTRATÉGIAS INOVADORAS PARA UMA APRENDIZAGEM ATIVA: ANÁLISE SOCIAL A PARTIR DE PODCAST
}

\author{
Raquel Rosan Christino Gitahy, Glaucia Aparecida Rosa Cintra, Leticia Rodrigues Biassoti, Luis Henrique \\ Ramos Alves \\ Universidade do Oeste Paulista - UNOESTE, Curso de Direito, Presidente Prudente, SP. E-mail: \\ raquelgitahy.rg@gmail.com
}

\begin{abstract}
RESUMO
Este artigo tem como objetivo demonstrar a capacidade dos professores e pais de se adaptarem a mudanças - resiliência, bem como analisar as reações dos envolvidos no processo de ensino e de aprendizagem em tempo de COVID 19. Para atingir o objetivo proposto foram analisados diversos Podcast que relatam como pais e professores estão se flexibilizando diante às aulas remotas para superar as dificuldades do momento e possibilitar que a educação ocorra nesse contexto de pandemia. $O$ ano de 2020 será lembrado como um ano de diversas mudanças da sociedade contemporânea. A pandemia causada pelo SARS-COV 2 infectou milhares de pessoas no Brasil e mundo, sendo o isolamento físico a melhor forma de prevenção contra o contágio, ocasionando transformações em vários setores da sociedade, inclusive o educacional, que tiveram que "abrir mão" do ensino presencial iniciando o ensino remoto para garantir o direito fundamental à educação. Por pesquisa bibliográfica e pesquisa documental, esta última baseada em Podcasts, constatou-se que há anos se discute o maior uso da tecnologia como instrumento facilitador da aprendizagem. Em tempo de aulas remotas, professores e alunos intensificaram o uso celulares WhatsApp e aplicativos, notebooks, internet e ambiente virtual de aprendizagem para possibilitar o acesso à educação.
\end{abstract}

Palavras-Chave: Direito à educação. SARS-COV 2. Aulas remotas. Podcast. Tecnologia.

\section{RIGHT TO EDUCATION AND INNOVATIVE STRATEGIES FOR ACTIVE LEARNING: SOCIAL ANALYSIS FROM PODCAST}

\begin{abstract}
This article aims to demonstrate the ability of teachers and parents to adapt to changes - resilience, as well as to analyze the reactions of those involved in the teaching and learning process in time of COVID 19. In order to achieve the proposed objective, several Podcasts were analyzed. report how parents and teachers are making themselves flexible in the face of remote classes to overcome the difficulties of the moment and enable education to occur in this context of a pandemic. 2020 will be remembered as a year of several changes in contemporary society. The SARS-COV 2 pandemic has infected thousands of people in Brazil and the world, with physical isolation being the best form of prevention against contagion, causing transformations in various sectors of society, including education, which had to "give up" the face-to-face teaching initiating remote education to guarantee the fundamental right to education. Through bibliographic research and documentary research, the latter based on Podcasts, it was found that for years the greatest use of technology has been discussed as an instrument that facilitates learning. During remote classes, teachers and students intensified their use of cell phones - WhatsApp and applications, notebooks, internet and a virtual learning environment to enable access to education.
\end{abstract}

Keywords: Right to education. SARS-COV 2. Remote classes. Podcast. Technology. 


\section{INTRODUÇÃO}

O ano de 2020 será considerado um marco para mudanças da sociedade contemporânea. A pandemia causada pelo vírus SARS-COV 2 infectou milhares de pessoas no mundo e no Brasil, exigindo medidas de controle. A preocupação com a saúde impôs a necessidade do afastamento social como forma de contenção da doença, conforme recomendação da Organização Mundial da Saúde - OMS.

Tal medida, ocasionou transformações e desdobramentos sociais, políticos, econômicos e também educacionais. A escola, principal ambiente do conhecimento formal, espaço em que, com a mediação do professor, ocorre a interação entre as crianças, adolescentes e jovens com o objeto de estudo, teve que responder ao contexto epidêmico.

A educação, direito fundamental social garantido pela Constituição Federal e Leis Ordinárias, não poderia deixar de ser garantida em tempo de pandemia, exigindo que a escola, profissionais da educação, estudantes e familiares se adaptassem a esse momento atípico e desafiador.

Como remediação às restrições impostas pelo afastamento social, as escolas, tiveram que "abrir mão" das interações pedagógicas propiciadas pelas aulas presenciais e deram início ao ensino remoto mediado pela tecnologia: celular e ambientes virtuais de aprendizagem AVA, exigindo uma grande capacidade adaptativa de todos os agentes envolvidos.

Para demonstrar a capacidade de se adaptar as mudanças e como os atores sociais envolvidos no processo ensino aprendizagem vêm agindo em tempo de COVID 19 foram analisados diversos Podcast que relatam como pais e professores estão se flexibilizando diante às aulas remotas para superar as dificuldades do momento e possibilitar que a educação ocorra nesse contexto de pandemia.

O podcasting ou mais conhecido como podcast é um processo midiático que se baseia na emissão sonora, sendo a internet o suporte essencial para o funcionamento e propagação das mensagens. Trata-se de uma modalidade de comunicação recente, os primeiros experimentos ocorreram nos anos 2000, inovando ao oferecer aos usuários alternativas diversas dos habituais em conteúdo sonoro, como a informação e a música (FLORES, 2014). A produção possui características próprias, dentre as quais destacam-se: os áudios são obrigatoriamente gravados, isto é, não ocorrem ao vivo, possuem periodicidade, podendo ser semanal, quinzenal, mensal, e ficam disponíveis para download (PINOCHET, 2014).

Os conteúdos são disponibilizados em sites, aplicativos exclusivos e cada vez mais nas plataformas streaming como Spotify, Deezer, dentre outros. As temáticas tratadas são as mais diversas possíveis, já que o ambiente digital permite que o usuário escolha o que mais the agrada, tais quais música, esporte, notícias, política, tecnologia, educação, cinema, ensino de idiomas. "O podcast é uma nova forma de comunicação sob demanda. O ouvinte decide o que consome e quando consome, a qualquer hora e a qualquer lugar do mundo" (VOLTARELI, et al, 2019, p. 32).

O aumento do consumo dessas mídias é decorrente do próprio modelo social do qual atualmente se integra, o ritmo frenético da execução das atividades diárias por vezes impede que se dê a devida atenção às telas ou as notícias, e o sentido que resta-se mais aguçado é a audição, podendo ser associado com outras atividades. Em uma pesquisa a Associação Brasileira de Podcasters revelou que $51 \%$ dos consumidores ouvem os conteúdos diariamente, por mais de $2 \mathrm{~h}$ e o momento com mais incidência são em trajetos (FERNANDES, 2020)

Em razão do disposto, os podcasts foram escolhidos para servirem de material de análise acerca da superação de obstáculos para a realização do sistema educacional em tempos de coronavírus, haja vista a farta disponibilização de áudios nesse sentido e a crescente demanda, trazendo a temática de forma díspar, relatos, depoimentos e opiniões por aqueles que vivenciam a educação em tempos de pandemia.

Assim, este artigo, tem como objetivo demonstrar a capacidade dos professores e pais de se adaptarem a mudanças - resiliência, bem como analisar as reações dos envolvidos no processo ensino-aprendizagem em tempo de COVID 19 a partir da visão de atores sociais expressas em Podcast.

\section{MÉTODO}

Para atingir o objetivo acima exposto, a coleta de dados foi realizada por meio da pesquisa bibliográfica e documental. Na pesquisa bibliográfica utilizamos livros, teses, dissertações e artigos de revistas qualis. A pesquisa documental foi baseada nos Podcasts, relacionando-se ao tema. 

qualitativa:

Em relação a abordagem opta-se pela

$$
\begin{aligned}
& \text { A abordagem de } \\
& \text { investigação qualitativa } \\
& \text { exige que o mundo seja } \\
& \text { examinado com a ideia de } \\
& \text { que nada é trivial, que } \\
& \text { tudo tem potencial para } \\
& \text { constituir uma pista que } \\
& \text { nos permita estabelecer } \\
& \text { uma compreensão mais } \\
& \text { esclarecida do nosso } \\
& \text { objeto de estudo } \\
& \text { (BOGDAN; BIKLEN, 1994, } \\
& \text { p. 49). }
\end{aligned}
$$

O contexto da pesquisa foi o ambiente virtual de aprendizagem em tempos de covid-19, buscando por informações em sistemas tecnológicos que fomentem e estimulem a discussão sobre a superação de obstáculos para a realização do acesso à educação durante a covid19. O que ratifica de forma mais robusta a escolha da abordagem, uma vez que "o pesquisador qualitativo buscará casos exemplares que possam ser reveladores da cultura em que estão inseridos" (GOLDENBERG, 2004, p. 50)

$\mathrm{Na}$ busca dos "casos reveladores" utilizou-se dos Podcasts disponibilizados na plataforma Spotify Studios que trata acerca da temática proposta de maneira diferente, com discussões interativas, opiniões e depoimentos de fácil entendimento, na busca pela compreensão das superações para que haja educação para todos em tempos de Covid 19.

A pesquisa utilizou-se das discussões vinda de jornalistas, membros da sociedade civil, bem como, especialistas no tema, registradas na plataforma Spotify Studios.

\section{RESULTADOS: ESTRATÉGIAS INOVADORAS PARA UMA APRENDIZAGEM ATIVA}

Há anos se discute na academia a necessidade de mudanças de estratégias de ensino e de aprendizagem que possibilitem mais motivação e interesse dos educandos pelas aulas, para que desenvolvam as habilidades e principalmente que sejam competentes para prosseguirem com seu projeto de vida profissional. Tal objetivo exigem um docente cada vez mais inovador e resiliente.

Alguns teóricos, como Moran (2015), já afirmavam a necessidade de um uso maior da tecnologia na educação, considerando o perfil do jovem do século XXI:
O que a tecnologia traz hoje é a integração de todos os espaços e tempos. O ensinar e aprender acontece numa interligação simbiótica, profunda, constante entre o que chamamos mundo físico e mundo digital. Não são dois mundos ou espaços, mas um espaço estendido, uma sala de aula ampliada, que se mescla, hibridiza constantemente. Por isso a educação formal está cada vez mais blended, misturada, híbrida, porque não acontece só no espaço físico da sala de aula, mas nos múltiplos espaços do cotidiano, que incluem os digitais. 0 professor precisa seguir comunicando-se face a face com os alunos, mas também digitalmente, com as tecnologias móveis, equilibrando a interação com todos e com cada um (MORAN, 2015, p. 16).

Durante a pandemia do COVID 19, os docentes atrelaram a metodologia ativa a tecnologia, pois o ensino remoto exigiu que os professores buscassem novos ambientes para o ensino, como o ambiente virtual de aprendizagem (AVA).

O Direito à Educação em tempos de Pandemia possibilitou a criação de estratégias inovadoras de ensino evidenciadas em vários podcasts, revelando a voz de diversos atores sociais envolvidos.

No Podcast - Café da manhã: a educação a distância não é para todos - produzido pela Folha de S. Paulo \& Spotify Studios (produtores: Renan Sukevicius e Jéssica Maes; jornalistas: Rodrigo Vizeu e Magê Flores) disponível na plataforma digital Spotify, frisou-se:

No começo do episódio você ouviu a voz da Márcia Silveira Sinegalia, mãe da Natália de 12 anos que está no 7o ano em um colégio privado de Curitiba no Paraná. A Natália está 
em casa a cada dois meses e tem assistido aulas e feito as atividades online usando ferramentas como - Google Classroom, na hora de estudar ela divide a mesa com a mãe que tá trabalhando em home office, elas têm ainda um aplicativo que a escola já usa há 03 anos e ajuda na comunicação de avisos;

Há 4.000 km de Curitiba há bons exemplos de funcionamento de ensino à distância em escolas públicas também: Olá, eu sou Maison, morador de Manaus, a minha filha é aluna de uma escola da rede estadual, ela tem 14 anos e está cursando o último ano do ensino fundamental, ela tem se esforçado muito, tem acompanhado as aulas pela tv, temos 03 canais de aulas online aqui;

No Amazonas onde o Teodoro mora é uma referência no ensino à distância, uma história que tem a ver com as enormes distâncias geográficas no Estado que tem a maior área do país. Há mais de uma década funciona por lá um centro de mídias do governo estadual que transmite aulas gravadas e ao vivo para o interior do Estado. Como boa parte das rodovias são rios, a tecnologia é aliada para levar o ensino de forma veloz as áreas isoladas;

Parar tirar as dúvidas a professora montou grupos de WhatsApp com os alunos.

Em Parintins, no interior de Amazonas que vive o professor José Colares Ferreira, ele é da rede estadual e dá suporte aos alunos que acompanham as aulas por outro veículo, a TV. Nas aulas ao vivo mantidas pelo centro de mídias de Manaus, é ele que organiza para que dúvidas sejam esclarecidas por exemplo (CAFÉ DA MANHÃ, 2020).

Já no podcast - O Assunto: Enem 2020 - o que vai acontecer com a prova? - produzido pelo G1, disponível no Spotify, com locução pela jornalista Renata Lo Prete, foi destacado pela Samanta Cunha, coordenadora do cursinho popular PreVest - Voluntários pela Educação de Salvador:

[...] a gente pensou em um formato que fosse mais democrático possível e que contemplasse o maior número de alunos possível, a gente trabalhou com ferramentas que eles já estavam familiarizados, já tinham um e-mail de grupo no Gmail e a gente já tinha um grupo no WhatsApp que é o nosso principal meio de contato com eles, então a gente está usando o Google Classroom, onde os professores colocam materiais e coisas para eles terem acesso (O ASSUNTO, 2020).

No podcast - Educaramba: professores e o desafio da educação na quarentena produzido pelo Instituto Singularidades, disponível no Spotify, com locução de Marcelo Ganzela, a professoras de escolas particulares da rede privada da cidade de São Paulo entrevistadas Patricia Minare e Deise Ramos, destacaram:

Os professores do ensino fundamental II e do ensino médio já estavam usando - Google for education como ferramenta nas suas aulas, eles já tinham participado de treinamento durante o mês de janeiro, então foi mais uma questão de adaptação no sentido de gravar vídeo aulas que 
isso sim é uma coisa que nós não fazíamos e que passamos a fazer, todas as nossas aulas remotas, a distância, estão sendo desenvolvidas por meio da videoconferência (EDUCARAMBA, 2020)

Muitas dessas estratégias utilizadas pelos professores contribuirão com a construção de uma aprendizagem mais autônoma e talvez, após a pandemia passar, muitos professores poderão refletir o quão esse momento, desafiador, gerou crescimento e mudanças positivas, tanto nos alunos, como nos docentes.

\section{DISCUSSÃO}

O Direito à educação é um dos direitos fundamentais/sociais mais relevantes do ordenamento jurídico brasileiro, já que por meio deste alcança-se o desenvolvimento pessoal e social do indivíduo. Encontra-se expressamente previsto no art. 205 da Constituição Federal (CF) como sendo um direito pertencente a todos, devendo ser garantido pelo Estado e pela família com a colaboração da sociedade, sendo efetivado por meio da educação básica obrigatória e gratuita dos quatro aos dezessete anos de idade - art. 208, CF (BRASIL, 1988).

A educação além de ser um direito fundamental/social é considerado inerente à dignidade da pessoa humana, incutido no art. 1ㅇ, inciso III, da Constituição Federal e ainda um Direito Humano com respaldo na Declaração Universal dos Direitos Humanos, documento internacional que influenciou de forma inequívoca a Magna Carta de 1988, observado no art. 26 da referida Declaração:

Todos os seres humanos têm direito à educação. $A$ educação será gratuita, pelo menos nos graus elementares e fundamentais. A educação elementar será obrigatória. A educação técnica-profissional será acessível a todos, bem como a educação superior, está baseada no mérito. A educação será orientada no sentido do pleno desenvolvimento da personalidade humana $\mathrm{e}$ do fortalecimento do respeito pelos direitos humanos e pelas liberdades fundamentais. A educação promoverá a compreensão, a tolerância e a amizade entre todas as nações e grupos raciais ou religiosos, e coadjuvará as atividades das Nações Unidas em prol da manutenção da paz (ONU, 1948).

Cumpre destacarmos que a concepção da educação como direito fundamental social na Constituição Federal de 1988 passou por um longo percurso histórico a saber.

De acordo com Ranieri (2018, p. 18-19):

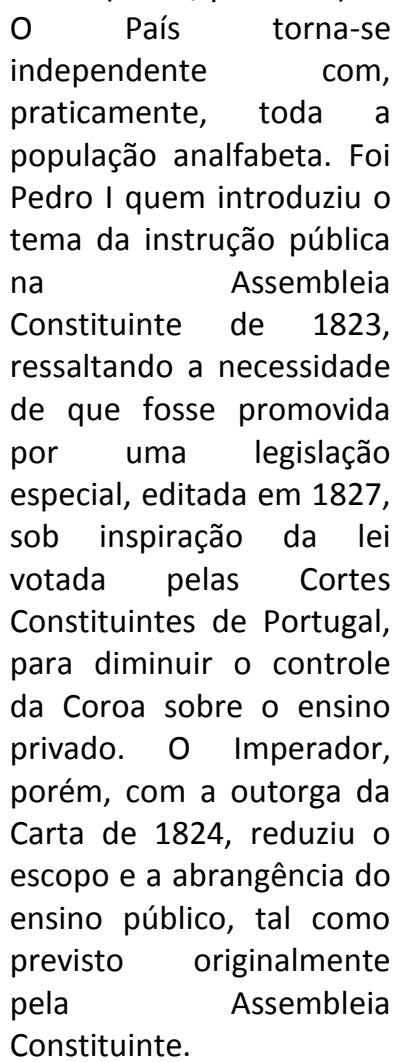

Apesar da Constituição de 1824 apresentar a temática de educação pública, a fez de maneira excludente, pois destinava-se, apenas, aos brasileiros livres ou libertos, excluindo os escravos e índios (RANIERI, 2018).

Somente em 1934 inicia-se uma nova fase histórica na abordagem do tema educação na Constituição Federal, concebendo como direito social, sendo dever do Estado garantir a todos a instrução. Além disso, trouxe dispositivos que organizam a educação nacional, específicas linhas gerais de um plano de educação a ser elaborado 
pelo Conselho Nacional de Educação (RANIERI, 2018; RAPOSO, 2020).

Getúlio Vargas instaura o Estado Novo e outorga a Constituição de 1937, que retrocede na questão do direito à educação, pois não universaliza a gratuidade. A Constituição Federal de 1946 manteve a educação como direito social, adotando medidas para ampliar o acesso ao ensino primário e determinou a obrigatoriedade e gratuidade. A ditadura militar imposta pós Golpe de 1964, promulga uma Constituição em 1967, com emenda em 1969, que assegura a educação universal, gratuita e compulsória dos sete aos quatorze anos para o ensino primário e para o secundário àqueles que demonstrarem não ter recursos financeiros para custear a educação (RANIERI, 2018).

Após um longo período de lutas sociais e reivindicações ocorridas nas décadas de 1970 e 1980, foi promulgada a Constituição Federal em 1988, a qual trata o direito à educação em cerca de vinte e dois artigos, os quais consideram esse como fundamental para o desenvolvimento nacional, pessoal e, principalmente, para construção de uma sociedade mais justa e solidária.

Além dos dispositivos constitucionais sobre o direito à educação, há, também, diversos Tratados Internacionais e leis ordinárias pátrias como a Lei no 9.394/96 -Lei de Diretrizes e bases da educação nacional - que traz a temática em seu artigo 3으, inciso I e IX, e na Lei no 8.069/90 Estatuto da Criança e do Adolescente - em seu artigo 53, inciso I.

Um exemplo de Tratado Internacional é o Pacto Internacional sobre Direitos Econômicos, Sociais e Culturais, ratificado e referendado pelo Brasil pelo Decreto no 591, de 06 de julho de 1992, que dispõe em seu artigo 13:

Os Estados Partes do presente Pacto reconhecem o direito de toda pessoa à educação. Concordam em que a educação deverá visar ao pleno desenvolvimento da personalidade humana e do sentido de sua dignidade e fortalecer o respeito pelos direitos humanos e liberdades fundamentais. Concordam ainda em que a educação deverá capacitar todas as pessoas a participar efetivamente de uma sociedade livre, favorecer a compreensão, a tolerância e a amizade entre todas as nações e entre todos os grupos raciais, étnicos ou religiosos e promover as atividades das Nações Unidas em prol da manutenção da paz (BRASIL, 1992).

Dessa forma, notamos que a educação tem por principal objetivo a busca da evolução humanística da sociedade, bem como a formação profissional adequada do indivíduo. Nessa perspectiva, Celso de Mello Filho (apud MORAES, 2016 , p. 879) afirma que “[...] a educação objetiva propiciar a formação necessária ao desenvolvimento das aptidões, das potencialidades e da personalidade do educando," completa ao dizer que o acesso à educação é uma das formas de realização do ideal democrático e que este processo tem por meta qualificar o educando para o mercado de trabalho e instrui-lo para o exercício consciente da cidadania.

O conhecimento é essencial o desenvolvimento social e para a garantia da dignidade da pessoa humana, colaborando para a afirmação dos direitos e na formação de uma consciência cidadã. Por meio da educação, é possível alcançar o progresso/mudança do Estado, pois tem ação libertadora e instrumentaliza o homem das amarras impostas pelo Poder Público, tornando-o livre de alienação, proporcionando reflexões sobre a realidade em que vive, tornando-se um agente social (FREIRE, 1967).

Destarte, após o discorrido, é possível afirmar que o direito à educação possui previsão constitucional e infraconstitucional sendo um direito fundamental de toda pessoa e possui respaldo em âmbito internacional, assegurando a todos o acesso à educação, devendo por isso ser garantido em qualquer tempo ou situação.

Os podcasts revelaram, pelos relatos dos atores envolvidos no processo de ensino e de aprendizagem, estratégias utilizadas para garantir o Direito Fundamental à Educação em tempos de pandemia, um contexto atípico o qual será lembrado por muitas e muitas décadas. Reinvenção, mudança, empatia, resiliência são palavras que podem caracterizar os depoimentos 
apresentados nos podcasts e sintetizar o momento desafiador a qual a educação passa nesses dias de quarentena.

\section{CONSIDERAÇÕES FINAIS}

A recomendação do afastamento social da Organização Mundial da Saúde como uma das estratégias de enfrentamento da pandemia do COVID 19, proporcionou uma grande mudança no planejamento pedagógico e na ação de ensino e de aprendizagem. Alunos e professores, acostumados com a aula presencial, que propicia uma aproximação e facilidade de intervenção pedagógica, tiveram que se reinventar com as aulas remotas.

Professores se superaram pesquisando e buscando novas estratégias de ensino à distância, elaborando roteiros formativos, realizando videoconferências, utilizando aplicativos de celulares e diversos softwares como citados nos depoimentos. Em seus lares, a busca por materiais e estratégias demonstrou a presença de um objetivo inerente ao professor: manter os estudantes motivados e engajados a essa nova proposta de ensino/aprendizagem, não desejada, mas necessária nesse período de pandemia, tentando mitigar, ao máximo, os impactos a aprendizagem que podem ocorrer neste momento.

Com essas estratégias, os professores têm atuado como mediador do conhecimento e isso poderá ter um reflexo positivo na aprendizagem dos alunos, que poderão ser mais autônomos na construção do seu conhecimento.

Mas não foi apenas o professor que demonstrou flexibilização e a capacidade de adaptação. Com as aulas remotas, pais e responsáveis começaram a participar mais da vida escolar dos seus filhos colaborando no processo de ensino e de aprendizagem. Crianças e jovens tiveram que aprender a se organizar para conseguir realizar todas as atividades propostas pelos professores.

Talvez, daqui a alguns anos, poderemos ouvir depoimentos de alunos que vivenciaram aulas remotas relatando que estas contribuíram no seu crescimento pessoal, possibilitando menos dependência do professor e mais autonomia na construção do conhecimento.

Pelos relatos dos podcasts concluímos que, neste momento de distanciamento social, professores e alunos, escola e pais, demonstraram superação e resiliência para o enfrentamento do problema. Do caos conseguiremos extrair o novo, uma mudança de paradigma para a Educação, mas um fato já é possível afirmar: a pandemia proporcionou um aprendizado para todos.

\section{REFERÊNCIAS}

BOGDAN, R. C.; BIKLEN, S. K. Investigação

qualitativa em educação. Porto: Porto Editora, 1994.

\section{BRASIL. Constituição (1988). Constituição da}

República Federativa do Brasil. Brasília: Senado Federal, 1988. Disponível em:

http://www.planalto.gov.br/ccivil_03/constituica o/constituicao.htm. Acesso em: 18 mai. 2020.

BRASIL. Congresso Nacional. Decreto no 591 , de 06 de julho de 1992. Regulamenta o Pacto Internacional sobre Direitos Econômicos, Sociais e Culturais. Diário Oficial da União, Brasília, DF, 06 de julho de 1992. Disponível em:

http://www.planalto.gov.br/ccivil_03/decreto/19 90-1994/d0591.htm. Acesso em: 18 maio. 2020.

\section{CAFÉ DA MANHÃ. A educação a distância não é}

para todos. Podcast. Locutores: Renan

Sukevicius, Jéssica Maes, Rodrigo Vizeu e Magê

Flores. Folha de S. Paulo ; Spotify Studios, 06 maio. 2020. Disponível em:

https://open.spotify.com/episode/2FEifKvdzX50N bM9Ojqqe2?context=spotify\%3Ashow\%3A6WRTz Ghq3uFxMrxHrHh1lo\&si=MKloEdDpQNygVsJ_W6 -gDQ. Acesso em: 29 jun. 2020.

\section{EDUCARAMBA: Professores e o desafio da} educação na quarentena. Locução: Marcelo Ganzela. De Instituto Singularidades. Spotify, 14 abr. 2020. Disponível em: https://open.spotify.com/episode/39V0xw7KcQr p4fWnc2JLGG?si=ppkqbOpYS--OfdjGVImubg. Acesso em: 29 jun. 2020.

FERNANDES, L. 0 que é podcast? Por que eles estão tão em alta atualmente? 2020. Disponível em: https://www.edialog.com.br/internet-2/oque-e-podcast/. Acesso em: 19 mai. 2020.

FLORES, T. C. P. A nova mídia podcast: um estudo de caso do programa matando robôs gigantes. 2014. 53 f. Trabalho de Conclusão de Curso (Jornalismo) - Universidade Federal do Rio de Janeiro, Rio de Janeiro, 2014. Disponível em: https://pantheon.ufrj.br/bitstream/11422/4379/ 1/TFlores.pdf. Acesso em: 19 maio 2020. 
FREIRE, P. Educação como prática da liberdade. 1. ed. Rio de Janeiro: Paz e Terra, 1967.

GOLDENBERG, M. A arte de pesquisar: Como fazer pesquisa qualitativa em Ciência Sociais. 8. ed. Rio de Janeiro: Record, 2004. Disponível em: http://www.ufjf.br/labesc/files/2012/03/A-Artede-Pesquisar-Mirian-Goldenberg.pdf. Acesso em: 20 maio. 2020.

MORAES, A. Direito Constitucional. 32. ed. São Paulo: Atlas, 2016.

MORAN, J. Mudando a educação com metodologias ativas. In: SOUZA, C. A. ; MORALES, O. E. (orgs). Convergências Mediáticas, Educação e Cidadania. Ponta Grossa: UEPG, 2015.

Disponível em:

http://www2.eca.usp.br/moran/wpcontent/uploads/2013/12/mudando_moran.pdf. Acesso em 19 jun. 2020.

O ASSUNTO. Enem 2020 - o que vai acontecer com a prova? Locução: Renata Lo Prete. G1 \& Spotify Studios, 13 maio. 2020. Disponível em: https://open.spotify.com/episode/4KvQBDkEMt1 2cNGCQK6UPY?si=JSOn6HZITOenEhokc2Hdjg. Acesso em: 29 jun. 2020.

ONU. Assembleia Geral das Nações Unidas.

Declaração Universal dos Direitos Humanos. 1948. Disponível em: https://nacoesunidas.org/direitoshumanos/decla racao/. Acesso em 19 jun. 2020.

PINOCHET, L. H. C. Tecnologia da informação e comunicação. Rio de Janeiro: Elsevier, 2014. Disponível em: https://integrada.minhabiblioteca.com.br/\#/book s/9788595153196/cfi/6/2!/4/2/2/2@0:0.00.

Acesso em: 19 maio. 2020.

RANIERI, N. Educação obrigatória e gratuita no Brasil: um longo caminho, avanços e perspectivas. In: RANIERI, N. B. S. ; ALVES, A. L. A. (orgs) Direito à educação e direitos na educação em perspectiva interdisciplinar. São Paulo:

Cátedra UNESCO de Direto à

Educação/Universidade de São Paulo (USP), 2018. https://doi.org/10.11606/9788553062003

RAPOSO, G. R. A educação na Constituição Federal de 1988. Revista Jus Navigandi, Teresina, v. 10, n. 641, 2005. Disponível em: https://jus.com.br/artigos/6574. Acesso em: 20 maio. 2020.

VOLTARELI, I. C. L. et al. Manas: podcast jornalístico com foco no público feminino. 2019. 353 f. Trabalho de Conclusão de Curso (Jornalismo) - Universidade do Oeste Paulista, Presidente Prudente, 2019. Disponível em: http://facopp.unoeste.br/facopp/manas-podcastjornalistico-com-foco-no-publico-feminino/. Acesso em: 19 maio 2020. 